\title{
ESTRATÉGIAS DE FLEXIBILIDADE NA CONSTRUÇÃO PRÉ-FABRICADA ${ }^{1}$
}

\author{
Geórgia de Souza Oliveira² \\ Clécio Magalhães do Vale ${ }^{3}$
}

DOI: $10.5752 / P .2316-1752.2018 v 25 n 37 p 150$

\section{Resumo}

A arquitetura pré-fabricada costuma ser relacionada à repetição massiva e à inflexibilidade construtiva. Em oposição a essas associações, faz-se aqui uma discussão de seus fundamentos e conceitos, analisam-se os aspectos culturais e tecnológicos de alguns países expoentes da pré-fabricação habitacional e se apresenta uma de suas empresas e seu modelo de produção. É discutida a flexibilidade na habitação e aborda-se, também, a metodologia Open Building, - uma das estratégias correntes para customizar os edifícios - que, aliada às estratégias de pré-fabricação, podem

\footnotetext{
1. Este artigo toma por base uma investigação em andamento na dissertação de Geórgia de Oliveira, no Programa de Pós-graduação em Construção Metálica da Escola de Minas da Universidade Federal de Ouro Preto (UFOP), sob orientação de Clécio Magalhães.

2. Arquiteta pela UFJF, mestranda no Mestrado Profissional em Construção Metálica da UFOP. E-mail: georgiasoliveira@yahoo.com.br

3.Arquiteto pela UFMG, mestre em Teoria e Prática de Projeto pela UFMG, doutor em Ciência e Tecnologia da Madeira pela UFLA, professor adjunto no curso de Arquitetura e Urbanismo e no Mestrado Profissional em Construção Metálica da UFOP. E-mail: cleciomagalhaes@gmail.com
} 
incrementar a customização da moradia.

Palavras-chave: Industrialização. Construção. Flexibilização. Arquitetura Aberta. 

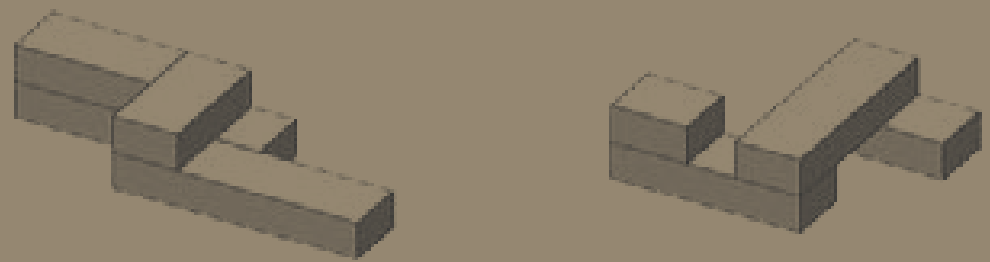

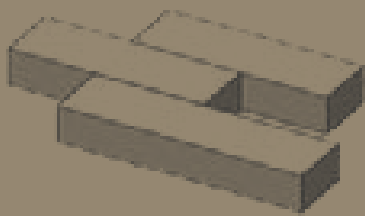

\section{FLEXIBILITY STRATEGIES IN PREFABRICATED} CONSTRUCTION

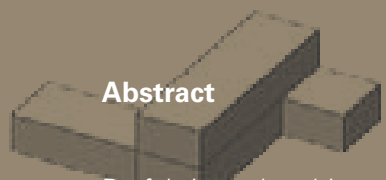

Prefabricated architecture is often related to massive repetition and constructive inflexibility. In opposition to these associations, a discussion of their foundations and concepts is outlined here. Cultural and technological aspects of some of the preponderant countries are analyzed, and one of their companies and their production model is presented. Flexibility in housing is discussed as well as the Open Building methodology - one of the current strategies for customizing buildings - which, along with pre-fabrication strategies, can increase the housing customization.

Keywords: Industrialization. Construction. Flexibility. Open Building.

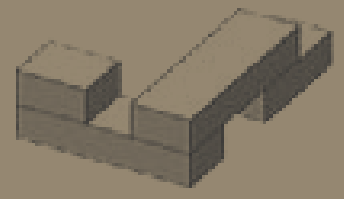

ESTRATEGIAS DE FLEXIBILIDAD EN LA CONSTRUCCIÓN PREFABRICADA

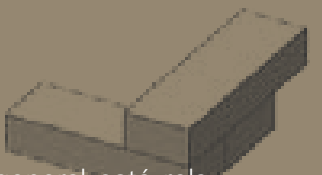

La arquitectura prefabricada en general está relacionada con la repetición masiva y la inflexibilidad constructiva. En oposición a esas asociaciones, se hace una discusión de sus fundamentos y conceptos, se analizan los aspectos culturales y tecnológicos de algunos países exponentes de la pre-fabricación habitacional, y se presenta una de sus empresas y su modelo de producción. Se discute la flexibilidad en la vivienda y se aborda también la metodología Open Building, - una de las estrategias corrientes para personalizar lós edificios - que, junto a las estrategias de pre-fabricación, pueden incrementar la personalización de la vivienda.

Palabras-clave: Industrialización. Construcción. Flexibilización. Arquitectura Abierta.
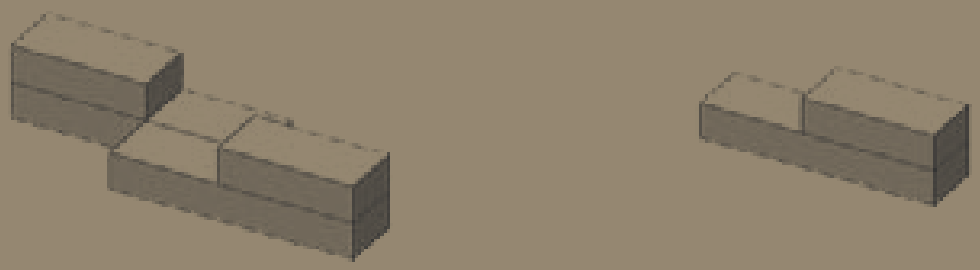


\section{Introdução}

Este artigo partiu da intenção de investigar a pré-fabricação como processo de produção para o segmento habitacional da construção civil, considerando seu potencial para edificações de maior qualidade, com custo e tempo de execução controlados, porém refutando a ideia de rigidez funcional em geral associada a esse sistema construtivo.

Smith (2010) aborda a pré-fabricação como uma tendência para uma nova lógica de construção, no sentido de mudar a economia e o modo de pensar arquitetura e planejamento, além de incrementar qualidade à produção.

Considerando-se essa assertiva, discutem-se aqui estratégias de processo de projeto, a fim de conferir maior flexibilização quanto à participação dos usuários na concepção do produto. Kapp e Oliveira (2006) afirmam que, na arquitetura, um processo de construção flexível, de ciclo aberto ${ }^{4}$, que permita alterações ao longo do tempo, oferece uma possibilidade muito maior de customização do produto em função das necessidades dos usuários (ainda que numa produção em massa) que no caso de um processo

\footnotetext{
4. No campo da construção civil, o ciclo aberto define uma produção cujos componentes são fabricados por múltiplos fornecedores, o que, segundo (KAPP e OLIVEIRA, 2006), estimula o desenvolvimento técnico e a concorrência de preços, logo, favorecendo o usuário.
} 
de construção de ciclo fechado 5 . Diante da inviabilidade de um sistema de produção em série para residências (como proposto pelos ideais fordistas e do movimento Moderno), um novo princípio pode ser explorado, com o foco na fabricação seriada de componentes, ao invés de unidades habitacionais completas.

Na segunda parte deste trabalho, discutem-se formas de se explorar a flexibilidade na arquitetura, a fim de prover habitações mais versáteis ou customizáveis conforme as demandas específicas dos usuários. Portanto, a flexibilidade na arquitetura pode ser uma ferramenta estratégica, no intuito de prover moradias que permitam maior versatilidade, seja para adaptação, ampliação/expansão ou, ainda, redução.

Nessa perspectiva, a metodologia do Open Building é abordada como uma estratégia para flexibilidade na construção pré-fabricada, com uma discussão a partir de referencial teórico acerca do tema e estudos de caso da Holanda e Japão, países que se destacam nessa prática. Objetiva-se demonstrar que a arquitetura aberta (ou Open Building) pode ser uma alternativa para vencer a barreira cultural que

5. No campo da construção civil, de modo oposto, o ciclo fechado define uma produção cujos componentes são fabricados por um único fornecedor, desestimulando o desenvolvimento técnico e a concorrência de preços, logo, sendo menos favorável ao usuário. 
se coloca sobre a pré-fabricação, além de permitir maior flexibilização e customização na arquitetura.

\section{Pré-fabricação}

\section{Um Breve Histórico da Pré-fabricação na Construção Civil}

Atualmente, três países lideram o segmento de construção pré-fabricada no mundo - Reino Unido, Escandinávia e Japão - que se destacam em inovação. Smith (2009) pontua que os Estados Unidos da América (EUA), apesar de deterem $26 \%$ do mercado de residências pré-fabricadas, perdem espaço para esses países que constantemente inovam em tecnologia, ao passo que esse índice, nesse país, é justificado em função de seu crescimento econômico. Para se compreender o destaque do Reino Unido, Escandinávia e Japão, e a correlação existente entre aspectos culturais e modelos produtivos de habitação, segue uma breve análise de suas experiências com a pré-fabricação de moradias.

\section{Reino Unido}

No ocidente, a colonização britânica dá início à pré-fabricação. Os britânicos não se familiarizaram com os materiais disponíveis nas colônias e a solução encontrada foi fabricar componentes na Inglaterra e transportá-los de navio para a 
montagem das construções nas colônias. Em 1624, as casas preparadas na Inglaterra e erguidas na vila pesqueira de Cape Anne deram origem à atual cidade de Massachusetts (ARIEFF, 2002, p. 13).

Já por volta de 1790, tem-se registro dos primeiros pré-fabricados enviados a Sidney, na Austrália, que serviriam de hospitais, armazéns e casas. Esse sistema construtivo, cujos abrigos eram estruturados em madeira, assim como os painéis de fechamento para paredes, forros e pisos, ficou conhecido como Balloon Frame. Há especulações de que os elementos de fechamento poderiam ainda ter sido feitos de lona ou painel em madeira com tratamento térmico (HERBERT, 1978, p. 6).

Em 1820, os britânicos enviam uma expedição à África com três chalés pré-fabricados em madeira para serem erguidos in loco. A estrutura dessas casas coloniais portáveis era simples, composta por painéis previamente preparados que se encaixavam e eram afixados à estrutura (HERBERT, 1978, p. 8).

Em 1830, John Manning, carpinteiro e construtor de Londres, projetou um chalé portável, confortável e que seria facilmente montado para seu filho, que imigraria para Austrália. Os painéis padronizados e intercambiáveis encaixavam-se entre os pilares de madeira (LOUDEN, 1839). A 
ideia de Manning era que uma pessoa comum pudesse carregar sozinha cada parte que compõe o abrigo. Assim, o sistema foi adotado para suprir as colônias britânicas.

O Chalé Manning pode ser considerado, portanto, uma meIhoria dos primeiros sistemas projetados pelos britânicos no sentido em que ele favorecia uma fácil construção. "O sistema do Manning pressupunha conceitos fundamentais de pré-fabricação, de coordenação dimensional e padronização." (HERBERT, 1978, p. 11-12).

Tais exemplos ilustram experiências de sucesso com a pré-fabricação na construção nesse país, refletindo a evolução no avanço tecnológico da construção do século XVII ao XIX, na Inglaterra, além da consolidação da cultura da pré-fabricação, cuja tecnologia foi transferida e aplicada pelos séculos seguintes à produção das habitações.

\section{Escandinávia}

A região geográfica da Escandinávia abrange Finlândia, Dinamarca, Suécia e Noruega, e a produção da pré-fabricação de casas nessa região é marcada por 3 eventos: a Revolução Industrial, o período da $2^{a}$ Guerra Mundial e o Pós-guerra.

A partir da Revolução Industrial, os conceitos de portabilidade e produção em massa de habitações passaram a ser ex- 
plorados com as serrarias/carpintarias produzindo em um novo ritmo. Por volta de 1917, aumentava a demanda por habitação e, já em 1930, mais de 20 fabricantes dispunham de catálogos de residências, expondo "casas kit" que poderiam ser escolhidas e encomendadas (SMITH, 2010).

No período Pós-guerra, aproximadamente, 70 companhias produziram mais da metade das habitações na Suécia. Em 1947, cerca de 17.500 casas foram pré-fabricadas, sendo esse um episódio importante, pois a pré-fabricação na construção começava a ser considerada não apenas pelo aspecto industrial como também pelo seu papel social. Com isso, surgem novos métodos de produção e uma variedade de protótipos, e observa-se uma escala comercial de produção na construção (SMITH, 2010).

Nos anos 1960 a pré-fabricação foi adotada como política habitacional nos países escandinavos. Nesse momento, a pré-fabricação era vista não só como a prática mais viável economicamente, mas, também, como a única solução aceitável politicamente para produção de habitações a custos acessíveis. Ainda nesse período, um grande avanço foi o fato de praticamente todas as novas construções serem planejadas a partir de múltiplos de 300 milímetros, o que evidencia uma tentativa de aplicação de medidas modulares para otimização dos processos de projeto e execução da obra. Em 1965, o Estado lança um programa de cons- 
trução massiva para 10 anos e, com isso, a produção das companhias impactou no trabalho dos arquitetos, que trabalhavam com determinada cadeia de suprimentos e aplicavam os componentes desta aos projetos (SMITH, 2010).

Ao fim dos anos 1960, os catálogos para compra de casas se tornaram prática comum, em oposição às casas projetadas individualmente por arquitetos. O resultado disso foi que a produção em massa de habitações tornou caótica a paisagem de comunidades nos subúrbios, na medida em que a abundância de variações era meramente superficial. Como estratégia para que o consumidor tivesse a sensação de estar adquirindo um produto único, os fabricantes lançaram os catálogos com as imagens das casas isoladas, inseridas num entorno no qual a paisagem natural seria seu único vizinho (SMITH, 2010).

Contudo, a produção de residências pré-fabricadas na Escandinávia obteve maior êxito em comparação aos EUA em função da maior aceitação social da tecnologia de pré-fabricação naquele país, onde não havia preocupação com a construção de casas portáveis, mas, sim, com um método de construção mais eficaz.

Dois fatores podem ser apontados para o sucesso da pré-fabricação na Escandinávia. Primeiro, o detalhamento de projeto, com adoção de conexões e articulações padroni- 
zadas, fabricadas industrialmente, gerando construções resistentes e duráveis, que são mais valorizadas pelo mercado. Segundo, a pré-fabricação na construção foi vista como mais vantajosa, pois permitiu menor custo à obra, logo, sistemas construtivos tradicionais tornaram-se obsoletos nesse país (SMITH, 2010).

\section{Japão}

Historicamente, os métodos de construção no Japão já se baseavam na produção em massa, embora construídos por artesãos. Além disso, a padronização de elementos construtivos é cultural nesse país, o que levou a estruturas com estética marcante e duráveis (SMITH, 2010).

No Japão, o tradicional sistema de construção residencial, chamado "post-and-beam", já poderia ser considerado um método de pré-fabricação. Nesse sistema, o espaçamento dos pilares era regular e eles receberiam os fechamentos de dimensões também padronizadas, sendo a medida do tatame utilizada como padrão (SMITH, 2010).

Após a Segunda Guerra Mundial, os métodos de construção pré-fabricados facilitaram o atendimento da demanda de reconstrução de casas e, assim como a Escandinávia, nas décadas de 50 e 60, o Japão produziu protótipos de residências que poderiam ser produzidas em massa. Hoje o país está em evidência por fazer da pré-fabricação seu prin- 
cipal método de construção. Em 2004, de 1.160.083 novas casas construídas no Japão, 159.224 eram pré-fabricadas, ou seja, em 1 a cada 7 novas casas construídas no Japão naquele ano foram usados métodos baseados em pré-fabricação (SMITH, 2010).

Sendo assim, o sistema de pré-fabricação no Japão apresenta uma série de possibilidades, não apenas uma única solução, e o sucesso do país está relacionado ao seu histórico de coordenação e técnicas eficientes que podem ser aplicadas para produção em massa, com suporte governamental e boas condições econômicas. Atualmente, mudanças demográficas e de estilo de vida clamam por constante evolução, colocando o desafio para o Japão de conciliar suas tradições com a crescente demanda industrial (SMITH, 2010).

\section{Fundamentos e conceitos relacionados à Pré-fabrica- ção na Construção Civil}

Bergdoll (apud SMITH, 2010) aponta que a pré-fabricação corresponde a um longo período da história da construção, que pode ser identificada desde a Antiguidade, incluindo os métodos empregados na construção de templos antigos e as estruturas de madeira. Controversamente, a história da pré-fabricação na Arquitetura é um tema de discussão da Arquitetura Moderna, que surgiu a partir da união entre Arquitetura e indústria. 
A ponte Coalbrookdale, erguida em 1807 sobre o rio Severn, no Reino Unido, foi um dos primeiros exemplos do emprego do ferro fundido na construção. Quase que completamente pré-fabricada, seus componentes eram padronizados, replicados e transportados ao local onde a ponte seria erguida. Essa tecnologia foi transferida para a pré-fabricação de edificações em ferro e, em meados dos anos 1800 , as casas inglesas e outros tipos de construções foram feitas com o uso de chapas pré-fabricadas em ferro fixadas por rebites (HERBERT, 1978).

Já o ferro corrugado foi uma inovação dos britânicos na construção, sendo adotado como material para coberturas e paredes. Inicialmente a corrosão era um problema, até que em 1837 começou a se aplicar o processo de galvanização. O ferro corrugado também foi empregado na Corrida do Ouro, em São Francisco, em meados de 1800 e, devido ao fluxo de pessoas atraídas para a região, surgiu uma urgente demanda por habitações (PETERSON, apud, SMITH, 2010). Smith (2010) destaca que o uso do ferro corrugado não se encerrou com a construção das "casas kit" no período da Corrida do Ouro, tendo sua aplicação continuado durante a Segunda Guerra Mundial para a fabricação dos abrigos militares Quonset e, mais tarde, também, em construções industriais ou mesmo em igrejas nas áreas rurais.

No período pós Segunda Guerra Mundial, a necessidade 
da reconstrução de cidades inteiras como parte do resultado da guerra novamente requisitou sofisticados sistemas construtivos, embora a qualidade das construções fosse frequentemente sacrificada (SMITH, 2010).

Chegando ao modernismo, arquitetos como Le Corbusier, Walter Gropius e Mies van der Rohe se questionaram porque a cultura da construção era resistente à transformação, ainda que já tivesse sido observada uma revolução na produção de objetos como roupas, sapatos, artigos para casa, automóveis e aviões. Esses arquitetos buscaram soluções criativas, com experimentações de novos materiais e métodos.

Historicamente, uma série de experimentos conduzidos por arquitetos, empreendedores e engenheiros ilustram a evolução na pré-fabricação, que ocorreu mediante os avanços conseguidos a partir da avaliação de tentativas bem sucedidas e das mal sucedidas também. Cada exemplo deixou uma lição, dando um direcionamento que pode ser seguido por arquitetos e profissionais da construção, conforme indicado por Smith (2010):

Lição 1. Sistemas proprietários não favorecem habitação de massa: Os sistemas proprietários falham economicamente, ainda que bem planejados e detalhados, pois são mais caros e dificultam reposições ou modificações.

Muitas vezes os arquitetos ou companhias têm com- 
petência técnica e estão preparados para enfrentar o mercado, no entanto, seus sistemas proprietários não se sustentam ao longo do tempo em função da demanda por estoque de material para reposição e manutenção da construção ao longo de seu ciclo de vida útil. Os sistemas proprietários tendem também a se estagnar em sua estética, dificilmente se adaptando a preferências individuais. Já os sistemas não-proprietários permitem, a partir de componentes padronizados e não patenteados, uma diversidade de possibilidades e até mesmo ampliações.

Lição 2. Pré-fabricação tem a ver com projeto e desenvolvimento de uma tecnologia: É importante pensar não apenas no projeto em si, de um bom produto, com seus detalhes de conexão e relação de materiais mas também planejar sobre o ponto de vista da produção. Os arquitetos costumam se ater mais ao projeto do que pensar na forma pela qual se dá a construção, porém, a tecnologia precisa ser desenvolvida, e não apenas planejada, necessitando de um ambiente de produção.

Outro ponto que representa um entrave à pré-fabricação é a preocupação dos arquitetos com a questão autoral, acreditando que sistemas pré-fabricados não deixariam em evidência este crédito. É consenso que cada projeto é único para determinado terreno e cliente, havendo uma barreira em se pensar em soluções que possam atender lugares diversos e um público maior e, neste sentido, este aspecto representa um entrave, uma vez que a pré-fabricação precisa de um ambiente de colaboração para se desenvolver.

Lição 3. Pré-fabricação tem mais a ver com um plano de negócios do que com um produto: A pré-fabricação, assim como qualquer negócio, está sujeita a oscila- 
ções do mercado, financiamento ou políticas econômicas, podendo fracassar.

Um outro fator corrobora esta afirmativa: os consumidores não se interessam por métodos de produção, engenhosidades ou sistemas de montagem sofisticados; a eles interessam mais características como durabilidade, conveniências e liquidez para revenda, portanto, há que se considerar técnica simultaneamente a um plano de mercado.

Lição 4. Circunstâncias devem justificar a pré-fabricação: Ao se elaborar um projeto/obra, a escolha do sistema construtivo deve considerar o contexto. A construção no canteiro nem sempre é a mais adequada e o contrário também é verdadeiro, logo, cada situação deve ser avaliada para receber soluções pré-fabricadas. Uma produção fora do canteiro deve considerar o cliente, o local e as condições de trabalho, evitando-se o risco das pretensões estéticas tecnológicas.

Lição 5. Pré-fabricação deve surgir de um processo integrado: Casos de insucesso ocorrem pela falta de um processo integrado desde o início do projeto, assim, ressalta-se a importância de uma equipe integrada que trabalhe orientada por responsabilidades distribuídas, com benefícios gerais e não promovendo visões individuais ou estéticas. Os benefícios da pré-fabricação não vêm somente da redução de custos individuais, mas também de efeitos secundários como redução de tempo, burocracia, tomadas de preços, dentre outros.

\title{
Um caso de produção customizada de habitação
}

\author{
Atualmente as soluções são baseadas em estratégias \\ de fabricação e transporte, sob inovação digital em prol \\ da relação entre planejamento e mercado. A evolução da
}


produção digital carrega certo otimismo quanto ao desenvolvimento de novas possibilidades para customização de massa ${ }^{6}$ na pré-fabricação.

\section{Resolution, 4 Architecture}

A companhia começou com a pré-fabricação nos EUA em 2002 a partir do desenvolvimento de uma série de tipologias de habitação com possibilidade de variabilidade dentro de um sistema padronizado. A Figura 1 ilustra módulos básicos utilizados para composição da habitação. O cliente escolhe a composição de módulos de sua preferência, o que resulta numa residência personalizada. O escritório trabalha com o método modular e já oferece ao cliente também algumas configurações de layout/planta baixa padronizados (Figura 2). Smith (2010) observa que a empresa tem desenvolvido customização de massa em Arquitetura, explorando a indústria de madeira encontrada nos EUA para fornecer uma arquitetura modular de alta qualidade.

Segundo Smith (2010), o processo da produção da empresa se desenvolve em 4 etapas:

6. A customização de massa proporciona aos usuários flexibilidade para adaptação e ampliação do produto final, ainda que produzida de maneira seriada. Ela traz consigo conceitos de produção em massa e automação para propiciar uma economia no escopo. Sob esse conceito, trabalha-se em prol de maximizar os benefícios da mecanização e métodos de produção automatizados, reduzindo custos com mão de obra e garantindo variabilidade e customização do produto final. 


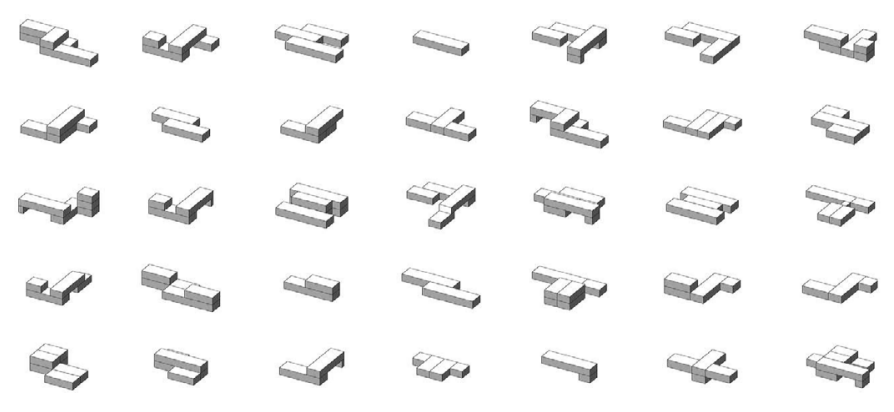

Figura 1 | Módulos

Fonte: SMITH, 2010

166

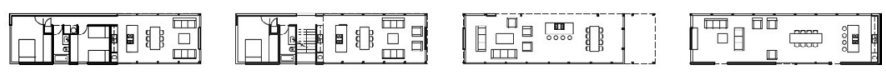

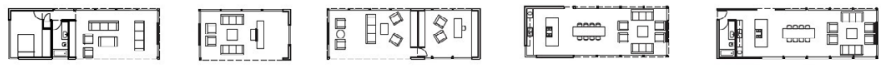
MODULES OF COMMUNIAL USE

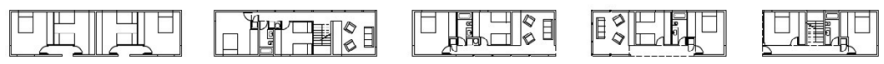

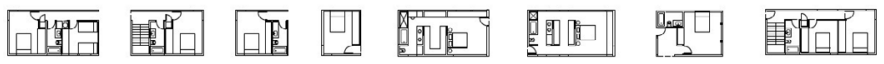
MODULES OF PRIVATE USE

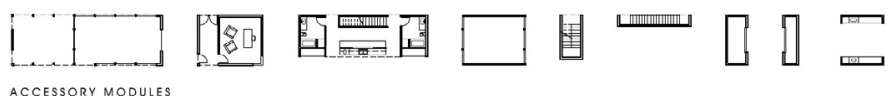

Figura 2 | Sistema modular da Resolution 4 Architecture: módulos residenciais para uso privado/comum e módulos acessórios.

Fonte: SMITH, 2010 
Fase 1: Projeto e documentação com o cliente (programa, adaptação do projeto modular, customização);

Fase 2: Coordenação de Engenharia/fabricante/contratante e aprovação legal;

Fase 3: Projeto básico/revisão/aprovação. Nesta etapa o cliente faz um depósito para que se inicie a produção. A medida que o fabricante adquire materiais e produtos, o contratante prepara o terreno. Dentro de uma a duas semanas o módulo básico está pronto;

Fase 4: montagem e acabamento da casa, que podem levar até 16 semanas em função da capacidade do contratante e da complexidade do terreno.

A proposta da empresa concilia um plano de negócios atraente para o consumidor, pois dilui o pagamento no tempo e oferece um repertório com vasta opção de dimensões e arranjos espaciais - embora não contemple modificações futuras, caso o morador deseje.

\section{Flexibilidade}

A flexibilidade na arquitetura deve ser explorada no intuito de prover habitações que permitam maior versatilidade, seja para adaptação, ampliação/expansão ou ainda redução.

Gausa (1998) relaciona o conceito de flexibilidade a uma maior polivalência e versatilidade do espaço, confrontando a diversidade tipológica e a flexibilidade espacial, contra a racionalização dos espaços e a uniformidade. Seu emprego responde a um novo perfil de vida, que ocasiona uma adaptação de um programa de necessidades tradicional: a 
família com poucos filhos ou nenhum, o que altera a vida doméstica para vida social, divisão das tarefas domésticas entre todos os membros da família, constante mudança no mercado de trabalho que cria instabilidade, provendo as casas alugadas. A habitação passa a ser entendida como um lugar de bem-estar e lazer, ao contrário da habitação comum que era concebida somente como uma necessidade social (GAUSA, 1998).

Para Abreu e Heitor (2007), a flexibilidade do espaço doméstico relaciona-se à capacidade do espaço físico de se adaptar à dinâmica do habitar. As autoras consideram cinco condições de adaptação do espaço físico da habitação, que resultam em práticas projetuais, tanto no nível de organização espacial, quanto aos processos construtivos:

1. Conversão: pela alteração na configuração espacial;

2. Polivalência: sem alteração na configuração espacial;

3. Expansão: por alteração de limites, seja na vertical ou na horizontal, com aumento de área;

4. Multifuncionalidade: por adaptação do espaço a vários usos;

5. Diversidade: pela variação tipológica num edifício.

Para as autoras, essas estratégias, quando utilizadas isoladamente, não auxiliam na geração de flexibilidade, ou seja, 
o ideal é a conjugação total ou parcial dessas estratégias nos vários elementos arquitetônicos (estrutura, fechamentos verticais/horizontais, instalações, acesso/circulação, configuração espacial).

Um edifício mais durável e com alta capacidade adaptativa apresenta um tempo mais estendido de uso de forma sustentável, seja para o primeiro morador, seja para as gerações futuras de moradores (LAMOUNIER, 2017).

JORGE (2012) pontua que a definição do conceito de flexibilidade é complexo, sendo explorada por diversos autores, em variadas áreas de conhecimento, envolvendo definições tais como adaptabilidade, participação, polivalência, multifuncionalidade, elasticidade, mobilidade, evolução e outros.

\section{Open Buildind}

$\mathrm{Na}$ intenção de se discutir estratégias de flexibilização da construção que atualmente estão em voga, apresenta-se nesta seção a metodologia do Open Building como uma ferramenta para incrementar customização às moradias.

O Open Building deriva da Teoria dos Suportes de Nicholas John Habraken. Nascido na Indonésia, em 1928, de ascendência holandesa, o arquiteto estudou na Universidade Tec- 
nológica de Delft entre 1948 e 1955. Em 1964, Habraken participou da criação do $\mathrm{SAR}^{7}$ (no holandês, Stichting Architecten Research; e no inglês, Foundation for Architect's Research), fundação voltada para a pesquisa arquitetônica, da qual foi diretor por dez anos.

Construção aberta é o termo usado para designar um conjunto de ideias sobre planejamento e construção de edificações, incluindo: a ideia de que usuários, bem como profissionais podem tomar decisões de planejamento; que a parte compartilhada de um edifício de multiocupação deve ser cuidadosamente distinguida de partes ocupadas individualmente; a ideia que a interface entre sistemas técnicos deve permitir realocação entre sistemas que desempenhem a mesma função (tal como acontece com diferentes sistemas aplicados à mesma base da construção); e a ideia que o ambiente construído está em constante transformação, requerendo que a mudança seja compreendida por profissionais para elaborar ambientes confortáveis e sustentáveis (HABRAKEN, tradução da autora).

No sistema aberto, os componentes industrializados são partes constituintes de uma edificação, permitindo

7. O SAR era composto não somente por arquitetos, mas também por contratantes e industriais, que juntos tinham como meta a industrialização da habitação, porém sob estratégias de projeto e construção de moradias em grande escala sem a uniformidade até então praticada no país. Sediado inicialmente na Universidade de Eindhoven e envolvendo boa parte da cadeia produtiva da indústria da construção nos Países Baixos, o SAR desenvolveu várias pesquisas sobre métodos de desenho à luz da teoria de Habraken, tanto para edifícios (SAR 65) quanto para tecido urbano e estrutura de cidades (SAR 73) (LAMOUNIER, 2017). 
alterações ao longo do tempo, conforme as necessidades do usuário ou possibilidades de se fazer modificações em função de um incremento de renda. Logo, essa abordagem é mais interessante que um sistema fechado, proprietário, com componentes específicos de determinado fabricante, que dificulta adaptações.

A produção industrial pode auxiliar na tomada de decisão individual na construção de habitações com maior qualidade, incrementando ainda agilidade ao processo construtivo. $\mathrm{Na}$ construção aberta, as decisões feitas para o público e para o indivíduo são processos distintos, mas não conflitantes sob a ótica da coordenação.

A teoria de Habraken, em resumo, defende a ideia de que o morador faça parte do processo de tomada de decisões. Kendall \& Teicher $(2000$, p.6) esclarecem que, para que esse processo ocorra, existem dois momentos no processo de produção: o coletivo, que equivale no projeto ao suporte, de decisão coletiva, fixo e geral; e o individual, que corresponde ao recheio, é mutável, dissociável, desacoplável ou desconectável e específico, de decisão de cada morador e que apresenta condições individuais ou personalizadas de habitabilidade. "A estrutura-suporte é " a construção que permite a provisão de habitações que podem ser construídas, alteradas e demolidas, independentemente das outras" (HABRAKEN, 2000, p.70). 
Lamounier (2017) explica que o suporte corresponde ao que, em geral é fixo, mas concebido de tal forma que permita a retirada, alteração, colocação ou expansão daquilo que corresponde ao recheio, sem grandes perturbações no sistema construtivo geral. Num edifício, geralmente, o suporte corresponde ao sistema estrutural (lajes, apoios, preferencialmente de forma independente das vedações); ao abastecimento geral de água, energia e gás; ao esgotamento sanitário e ao sistema de drenagem, com parte das instalações elétricas, telefônicas, de segurança, de água e de lixo, normalmente dispostas nas áreas de uso coletivo e em shafts; às circulações de uso coletivo (vertical e horizontal); ao mínimo necessário, seguro e durável 172 (um século ou mais), para que o morador receba uma unidade habitacional e complete com aquilo que dependa exclusivamente de sua escolha e decisão.

Um suporte não é meramente um esqueleto. Ele não é neutro, mas sim habilita a arquitetura. Ele é mais do que serviço, do que um meio ambiente construído inserido em uma paisagem: um suporte é configuração física que oferece espaço e possibilidade de produzir moradias com o menor número de restrições possível, exigindo o mínimo de trabalho (HABRAKEN, 2011, p.72).

Lamounier (2017) complementa, ainda, que o suporte equivale fisicamente a elementos com qualidade $e$ durabilidade de longo prazo e recheio equivale fisicamente 
a elementos com qualidade e durabilidade de curto e médio prazo. Para que ocorra compatibilidade entre suporte e recheio, todos os componentes construtivos devem estar coordenados modularmente e apresentar características de conectividade do tipo plug-and-play.

\begin{abstract}
Já o recheio pode corresponder fisicamente ao arranjo interno dos cômodos, com paredes ou divisórias, esquadrias internas e externas (quando a fachada é considerada recheio), forro, pisos, acabamentos em geral, luminárias, pontos e ramificações das instalações elétricas, hidráulicas, equipamentos de cozinha e banheiro - inclusive permitindo mudança dessas áreas molhadas -, mobiliário, sistemas mecânicos de aquecimento, ventilação, ar condicionado, telecomunicação e segurança quando for o caso (LAMOUNIER, 2017, p . 90).
\end{abstract}

A Figura 3 expõe a ideia de que os usuários fazem parte do processo construtivo do ambiente em diversos níveis, participando com profissionais, opinando sobre um ambiente construído em constante desenvolvimento, o 


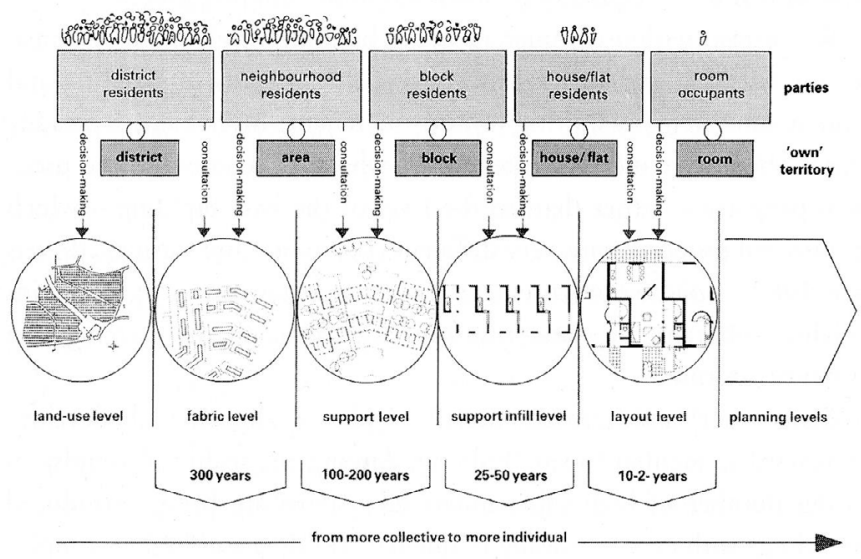

Figura 3 | Principais níveis de planejamento e a participação dos usuários. Fonte: KENDALL, 2004

que pode reduzir desperdícios e conflitos.

Em habitações multifamiliares podem surgir conflitos nas tomadas de decisão quanto às partes compartilhadas e individuais da edificação, logo, a maior independência das unidades autônomas pode ser uma solução para maior oferta de flexibilidade.

\section{Precedentes vernáculos: Holanda e Japão}

A Holanda e o Japão tiveram e têm grande influência tanto na elaboração original da teoria de Habraken quanto no desenvolvimento do movimento Open Building. Conforme 
Habraken (1979), nas tradicionais casas holandesas, primeiro construía-se as fachadas, com o telhado e estrutura de portas e janelas e depois o arranjo interno da habitação

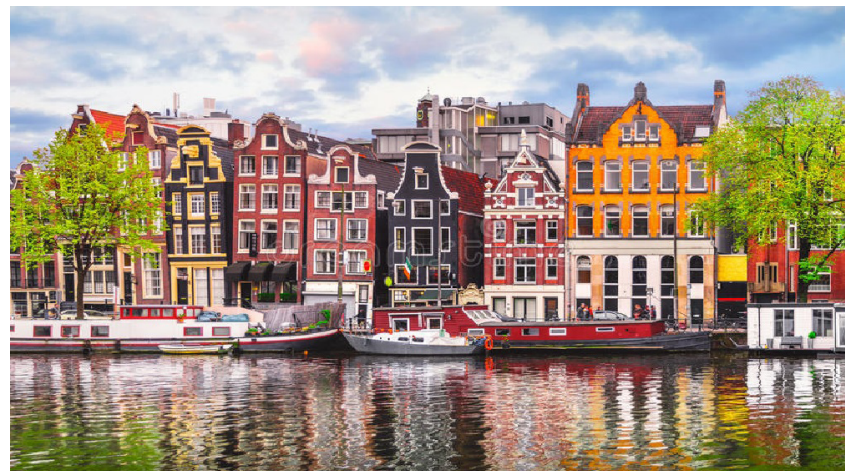

Figura 4 | Casas dos canais tradicionais holandeses, fachadas e plantas.

Fonte: DREAMSTIME ${ }^{8}$

(Figura 4).

Habraken (2000) relaciona esse modo de construção ao das casas vernáculas gregas, cujo envelope é uma alvenaria pesada com estrutura do telhado em madeira, havendo internamente um mezanino de madeira, que cria dois

8. Disponível em: https://pt.dreamstime.com/foto-de-stock-casas-holandesas-da-dan\%C3\%A7a-de-amsterd\%C3\%A3o-sobre-o-rio-amstel-image92873811. Acesso em 02/10/2018. 
pisos. Segundo o autor, "isso é como uma pequena casa dentro de uma grande casa" (HABRAKEN, 2000, p. 101).

Ou seja, como a estrutura das casas é independente uma da outra, uma casa pode ser demolida ou modificada sem perturbar indevidamente cada vizinho no tecido urbano. As paredes contínuas, localizadas na divisa dos terrenos com as vias, por cercar as habitações em conjunto com paredes perpendiculares às ruas, independentes umas das outras, tornam as intervenções individuais ou urbanas mais facilitadas.

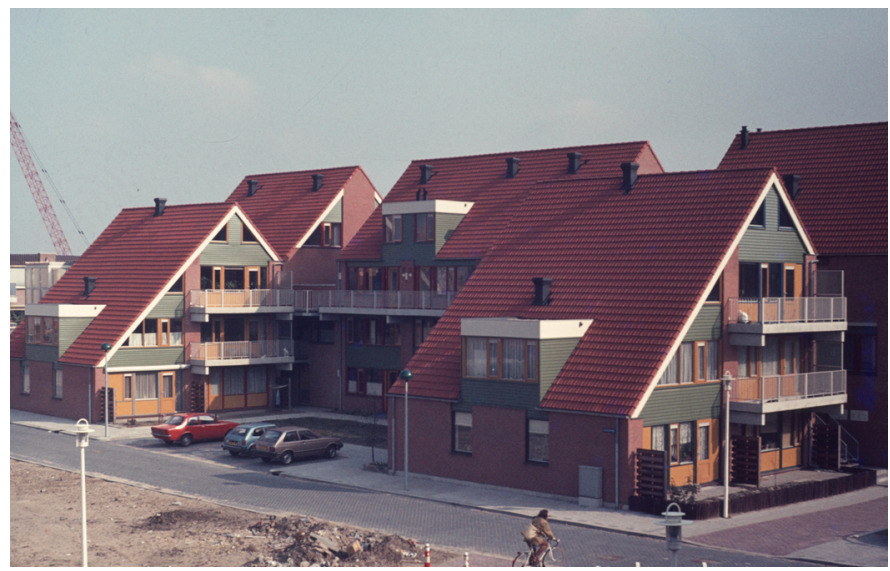

Figura 5 | Conjunto residencial Molenvliet. Fonte: THEMATICDESIGN ${ }^{9}$

9. Disponível em: http://thematicdesign.org/open-building-experience-2-lunetten-4d-utrecht-the-netherlands-1981-82/. Acesso em 02/10/2018. 
Uma forma de organização que tradicionalmente veio ocorrendo na história da conformação do desenho urbano em toda a Holanda (LAMOUNIER, 2017, p . 109).

Molenvliet é um caso clássico de construção tipo suporterecheio (Figura 5) e, de acordo com Kendall (2004), o projeto foi vencedor de uma competição para 2800 habitações e se destacou pela combinação de planejamento urbano, arquitetura e processo participativo. A proposta permite uma ampla variedade de tamanhos de unidades e inclui elementos característicos da arquitetura e desenho urbano holandeses, como telhados inclinados, janelas de madeira, portas em pátio e usos mistos (há ainda um consultório médico, pequenas lojas e escritórios comerciais).

Suporte consiste de uma estrutura de concreto em forma de "túnel ou pórtico" moldada in loco, com aberturas nas lajes para passagem e compartilhamento do sistema de instalações e escadas internas. Parte da fachada nesse projeto é considerada elemento de recheio, sendo disponibilizados para os moradores kits variados de componentes em madeira préfabricada, aludindo à variedade das fachadas das casas holandesas nos canais. As habitações estão organizadas de forma justaposta, distribuídas em blocos de 2 a 4 pavimentos, conformando um conjunto mais horizontalizado ao redor de pátios de acessos, com quintais ou terraços elevados. Há uma prioridade oferecida ao fluxo de pedestres nas áreas abertas (LAMOUNIER, 2017, p .102).

"Já as construções tradicionais japonesas usavam, desde 
séculos atrás, telas deslizantes e desmontáveis, além dos famosos pisos tatame, removíveis entre estruturas para criar ambientes flexíveis" (KENDALL \& TEICHER, 2000, p.28).

Werner (1994, p.91) pontua que nos séculos VII e VIII já era possível encontrar casos de clara distinção entre estrutura e elementos de partição interna. A própria família definia o layout interno, tendo como referência o tatame e, além disso, o uso de divisórias deslizantes facilitava arranjos espaciais mais abertos, seja para integrar ou dividir ambientes. Hoje o Japão é referência em sistemas construtivos do tipo suporte e recheio.

O projeto do edifício Next 21 (Figura 6) contempla 18 unidades habitacionais e atende a famílias urbanas para habitação mais confortável no Japão no século XXI. Concebido por Osaka Gas em parceria com equipe, o projeto experimenta fontes de energia e equipamento de tratamento de lixo e alto grau de flexibilidade, conseguido por meio da coordenação, permitindo alteração de fachada 


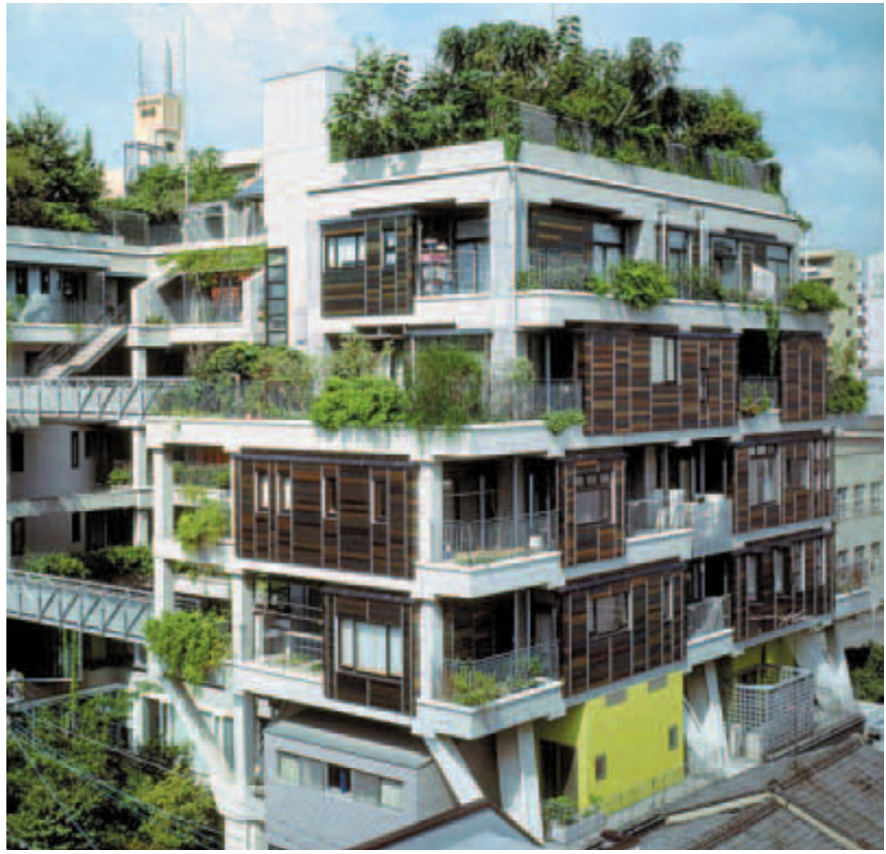

Figura 6 | Conjunto residencial no Japão. Next 21, Osaka, Japão, 1994 - presente Fonte: LACIUDADVIVA ${ }^{10}$

e layouts. Há espaço para instalações entre o piso elevado e sobre o forro, além de subsistemas independentes, que podem ser ajustados com grande autonomia.

10. Disponível em: http://www.laciudadviva.org/blogs/wp-content/uploads/2011/02/ Foto2..jpg. Acesso em 02/10/2018. 
Em Osaka, Japão, esse edifício é um dos exemplares de Open Building mais discutidos. Sua estrutura-suporte evidencia com clareza a forma física do par suporte e recheio, aplicando ainda os princípios relacionados à coordenação modular ${ }^{11}$. O projeto e a construção foram concebidos em duas fases: na primeira, partes estruturais principais de longa duração (pilares, vigas e pisos) e, na segunda, o interior, cujos elementos de curta duração deveriam satisfazer às necessidades dos usuários. Com pé-direito elevado, todas as instalações, como dutos de gás, água e eletricidade ficavamm em pisos elevados ou em tetos falsos, com fácil acesso para manutenção ou modificações.

O Next 21 é um caso de sucesso em que se pode verificar um misto da Teoria de Habraken com tradições locais e participação dos ocupantes diretamente nos processos de projeto e construção. O projeto concilia a flexibilidade

11. A Coordenação Modular visa compatibilizar elementos construtivos (definidos em projeto) e componentes (definidos pelos fabricantes); reduzir a variedade de medidas utilizadas na fabricação de componentes; simplificar a coordenação dimensional nos projetos das edificações, que hoje é elaborada caso a caso; simplificar o processo de marcação no canteiro de obras para posicionamento e montagem de componentes construtivos; reduzir cortes e ajustes de componentes e elementos construtivos, entre outros aspectos. 


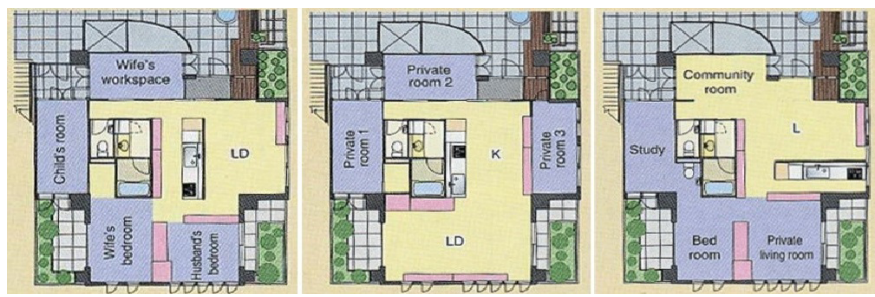

Figura 7 | Propostas de intervenção na unidade 405 do edifício Next 21, para abrigar familiares com necessidades distintas.

Fonte: OSAKA GAS ${ }^{12}$

para adaptação das unidades individuais às necessidades e estilo de vida dos usuários com a incorporação de sistemas construtivos flexíveis, que acarretam economia de recursos, durabilidade e sustentabilidade (Figura 7).

Diante da metodologia discutida, compreende-se que, de fato, o Open Building alinha-se a práticas sustentáveis na medida em que racionaliza o processo de construção, uma vez que o ambiente construído não é estático, pelo contrário, é dinâmico tal qual a atual dinâmica de vida em sociedade, que acarreta novas formas de viver e, por consequência, novas formas de habitar. Dos estudos de caso vernáculos apresentados anteriormente, entende-

12. Disponível em <http://www.osakagas.co.jp/rd/next21/htme/ferz2e.htm>. Acesso em setembro de 2018 
se que tradição e boas práticas de construção estão intrinsicamente relacionadas, deixando uma referência sobre novas possibilidades para se prover moradias com maior qualidade e autonomia aos usuários, a partir da assimilação dos preceitos do Open Building.

\section{Conclusão}

No contexto da construção pré-fabricada, a importância do processo de projeto torna-se ainda mais evidente, uma vez que esse tipo de sistema construtivo não admite improvisações, pois, do contrário, a eficácia prevista quanto a custos, tempo de execução e qualidade do produto final é comprometida. Ainda que inicialmente a pré-fabricação possa não ser o caminho mais barato, a qualidade e os impactos ambientais podem ser mais facilmente alcançadas por meio de um maior controle do produto.

A construção pré-fabricada demanda maior integração entre os profissionais envolvidos nas diversas disciplinas referentes ao projeto, sendo exigido maior grau de detalhamento a fim de que se evitem incompatibilidades, uma vez que as soluções projetuais estão muito mais diretamente relacionadas às etapas de fabricação, transporte e montagem da estrutura que em outros sistemas construtivos. Nesse sentido, o planejamento da flexibilidade da arquitetura já deve constar desde a etapa de projeto, viabilizando-se futuras alterações. 
Como a pré-fabricação foca mais no produto que no serviço, a investigação do processo de produção pode estabelecer estratégias para que, na prática, uma obra para adaptação, ampliação ou redução ocorra com o menor impacto possível para o morador, tanto em relação ao que representa o inconveniente da gestão e execução de uma obra de reforma, quanto à facilidade para que essa obra ocorra.

O processo de projeto para a arquitetura aberta deve incorporar sistemas construtivos flexíveis, gerando economia de recursos, durabilidade e sustentabilidade, na medida em que, sendo previsíveis e planejadas as modificações, evitam-se desperdícios em função da demanda por adequações ao novo perfil de vida dos usuários.

Os sistemas proprietários não são os mais apropriados para a prática do Open Building, uma vez que encontram maior dificuldade para adaptabilidade às preferências individuais. Os componentes da construção podem ser padronizados, facilitando o processo de projeto e execução e, ainda assim, oferecer grande variabilidade e flexibilidade.

É preciso planejar não apenas a construção em si, mas, também, considerar a montagem/execução essencial para a prática da arquitetura aberta, tendo em vista a oferta das 
possibilidades de flexibilidade (mesmo que imprevisíveis), bem como os meios para viabilizar tais modificações, seja para adaptação, ampliação/expansão, ou redução.

O Open Building pode ser usado de forma estratégica no mercado, considerando o fato de que interessa aos usuários a aquisição de um produto durável, que acompanhe transformações do grupo familiar e ofereça flexibilidade e economia de recursos.

É válido destacar que o Open Building pode ser adotado como estratégia de flexibilidade não apenas na construção pré-fabricada como também aplicado a outros sistemas construtivos. Sua metodologia pode ser até mesmo empregada em retrofits e, para o sucesso dessas empreitadas, seja na construção pré-fabricada ou na construção tradicional, é fundamental o planejamento para que ocorra a flexibilização (projeto e execução). Além disso, precisa se envolver nas tomadas de decisão não apenas os profissionais, como também os usuários, garantindo que se evitem desperdícios e que, de fato, a satisfação e a qualidade de vida no ambiente construído sejam efetivadas.

Das definições de suporte e recheio discutidas nesse texto, conclui-se que não existe uma categorização definitiva, sendo variáveis tais elementos e que, portanto, devem ser analisados caso a caso. Isso é relevante para que se 
considerem estratégias de projeto que, de fato, permitam flexibilidade mediante a compatibilização e a articulação do suporte-recheio. Nesse sentido, a coordenação modular pode ser uma ferramenta fundamental, lembrando que o mercado precisa estar provido de componentes e elementos construtivos compatibilizáveis.

Ferramentas como softwares simples podem aperfeiçoar a interface profissionais/ usuários nas tomadas de decisão em conjunto, facilitando soluções individuais e coletivas.

Como se pôde ver no histórico dos casos de pré-fabricação (Reino Unido, Escandinávia e Japão) e nos precursores do Open Building (Holanda e Japão), a aceitação de tais práticas se deu em certa medida em função da aceitação cultural, da inovação tecnológica e do suporte governamental. Isso lança um pressuposto de que, para maior difusão do Open Building no Brasil, inovação em tecnologia e o aporte governamental são indispensáveis, pois trazem maior aceitação desse sistema e prática construtiva.

É preciso disseminar a prática do Open Building no meio acadêmico e no mercado para se efetivar a Teoria dos suportes como uma estratégia de flexibilidade para a arquitetura. Logo, o desafio para os arquitetos não é revolucionar, mas evoluir no processo de projeto para 
construção pré-fabricada e práticas de arquitetura aberta, cumprindo seu papel para vencer a barreira cultural que ainda existe.

\section{Referências}

ABREU, R; HEITOR T. Estratégias de Flexibilidade na Arquitectura Doméstica Holandesa: da conversão à multifuncionalidade. 2007.

ARIEFF, A; BURKHART, B. Prefab. Gibbs Smith, 2002.

BERGDOLL, Barry. Home Delivery: fabricating the modern dwelling. The Museum of Modern Art, 2008.

CMS. Disponível em:<http://cms.bsu.edu/Academics/ CollegesandDepartments/CAP/CentersOutreach/BuildingFutures/ OpenBId/Residential//media/WWW/DepartmentalContent/BFl/ ThesisCh4.ashx>. Acessado em 01/09/2018

DREAMSTIME. Disponível em: <https://pt.dreamstime.com/foto-destock-casas-holandesas-da-dan \% C3\% A7a-de-amsterd\% C3\% A3osobre-o-rio-amstel-image92873811 > . Acessado em 02/10/2018.

GAUSA, Manuel. Housing, novas alternativas, nuevos sistemas. Barcelona: Actar, 1998.

HABRAKEN, N. John. Disponível em: <www.habraken.com/john/ obintro>. Acesso em: 07 jul. 2016.

HABRAKEN, Nicholas John. Supports: an alternative to mass housing. UK: The Urban International Press, 2000.

HABRAKEN, N.J.; BOEKHOLT, J.T.;DIENENS, P.J.M.; THYSSEN, A.P [Habraken et al.]. El Diseño de Soportes. Barcelona: Gustavo Gili, 1979.

HABRAKEN, Nicholas John. Structure of the ordinary: form and control in the built environment. Cambridge (MIT):The MIT Press, 2000. 
HERBERT, Gilbert. Pioneers of Prefabrication: The British Contribution in the Nineteenth Century. Baltimore: Johns Hopkins University Press, 1978.

JORGE, L. Oliveira. Estratégias de Flexibilidade na Arquitetura Residencial Multifamiliar. 2012. 512 f. Tese (Doutorado em Arquitetura e Urbanismo), USP, São Paulo. 2012.

KAPP Silke; OLIVEIRA Natália M. A. Produção seriada e individualização na arquitetura de moradias. Belo Horizonte, 2006. Disponível em: <http://www.pucmg.br/documentos/arquitetura_14_ artigo10.pdf>. Acesso em: 21 jul. 2016.

KENDALL, Stephen. An Open Building Strategy for Achieving Dwelling Unit Autonomy in Multi-unit Housing. Ball State University, 2004.

KENDALL, Stephen \&TEICHER, Jonathan. Residential Open Building. New York: E \& FN Spon, 2000.

KIERANTIMBERLAKE. Disponível em: < http://www.kierantimberlake. com/pages/view/20/loblolly-house/parent:3>. Acesso em: 13 jul. 2016.

LACIUDADVIVA. Disponível em: <http://www.laciudadviva.org/blogs/ wp-content/uploads/2011/02/Foto2..jpg> Acesso em: 04 out. 2018.

LAMOUNIER, R. Fonseca. Da autoconstrução à arquitetura aberta: o Open Building no Brasil. 2017. 513f. Tese (Doutorado em Arquitetura e Urbanismo), UFMG, Belo Horizonte. 2017.

LOUDEN, John C. The Encyclopedia of Cottage, Farm, and Villa Architecture and Furniture. Londres, 1839.

OSAKAGAS. Disponível em <http://www.osakagas.co.jp/rd/next21/ htme/ferz2e.htm>. Acesso em setembro de 2018.

SMITH, Ryan E. History of Prefabrication: A Cultural Survey. Salt Lake City, 2009.

SMITH, Ryan E. Prefab Architecture: A Guide to modular design and construction. Wiley, 2010.

THEMATICDESIGN. Disponível em <http://thematicdesign.org/openbuilding-experience-2-lunetten-4d-utrecht-the-netherlands-1981-82/> Acessado em 02/10/2018. 
WERNER, Jörg. Adaptacions quotidianes. In: Quaderns

D'Arquitectura Urbanisme. Barcelona,n.202,1993. Disponível em: <http://www.raco.cat/index.php/QuadernsArquitecturaUrbanisme/ article/view/233980 > . Acesso em setembro de 2018 